\title{
Primena elektrofilterskog pepela modifikovanog sa cementom za uklanjanje arsena iz vodenih rastvora
}

$\mathrm{E}$ lektrofilterski pepeo (FA) nastaje kao nusproizvod sagorevanja uglja može se koristiti kao ad-sorbent za uklanjanje teških metala iz otpadne vode $[1,2]$. Svojstva pepela određuju njegovu dalju namenu i zavise od vrste $i$ kvaliteta uglja koji sagoreva $[3,4]$. Prema hemijskom sastavu pepela, u skladu sa standardom ASTM C618 pepeo se klasifikuje u F i C klasu. Klasifikacija je izvršena prema sadržaju oksida silicijuma, gvožđa, aluminijuma i kalcijuma. Pepeo iz Srpskih termoelektrana su F klasa iako nastaju sagorevanjem lignita. Pepeo ima pucolanska svojstva [3] koja se kod pepela F klase mogu poboljšati dodatkom hemijskih aktivatora kao što su kalcijum hidroksid ili cement. Prisustvo arsena u vodi ima štetno dejstvo na zdravlje ljudi i uzrok je brojnih oboljenja [5]. Uklanjanje arsena može se vršiti različitim metodama [6], brojni literaturni radovi ukazuju da je proces adsorpcije efa-kasna i ekonomski prihvatljiva metoda $[7,8]$. Ispitivanje primene FA sa cementom pokazala mogućnost uklanjanja selena iz vodenih rastvora [9].

Cilj ovog rada jeste ispitivanje uklanjanja $\mathrm{As}(\mathrm{V})$ jona primenom elektrofilterskog pepela i hemijski modifikovanog FA sa cementom (MFAC).

\section{Eksperimantalni deo}

Adsorpcioni eksperimenti vršeni su u laboratorijskim uslovima u šaržnomsistemunatempera-turamaod $25,35 \mathrm{i} 45^{\circ} \mathrm{C}$. Standardnirastvor $\mathrm{As}(\mathrm{V})$ pripremljen je korišćenjem dejonizovane vode i $\mathrm{Na}_{2} \mathrm{HAsO}_{4}$ - $7 \mathrm{H}_{2} \mathrm{O}$ (Carlo-Erba). Kao adsorbenti korišćeni su elektrofilterski (leteći) pepeo iz termoelektrane Kostolac (FA) i modifikovani pepeo uz dodatak $5 \%$ cementa (MFAC). Početna koncentracija rastvora arsena je $10,0 \mathrm{mg} / \mathrm{L}$, varirana je masa adsorbenta $0,5,1,2,4,6,8$ i $10 \mathrm{mg}$. Adsorbent i $7 \mathrm{ml}$ standardnog rastvora As(V) sjedinjeni su u laboratorijskim čašama koje su postavljene na orbitalnom šejkeru (Rotamax 120, Heidolph Instruments) u trajanju od 180 min. Nakon mešanja svaka suspenzija ostavljena je da se istaloži, rastvor je pažljivo odliven iz čaše i profiltriran na filtarskom papiru (MF Millipore membrane filter, 0,45 $\mu \mathrm{m}$ ) i zakišeljen koncentrovanom $\mathrm{HNO}_{3}$. Određivanje koncentracije arsena izvršena je korišćenjem induktivno spregnute plazme sa masenom spektrometrijom (ICPMS) na uređaju Agilent 7500ce ICP-MS (Valdbron, Nemačka). Adsorpcioni kapacitet adsorbenta, odnosno masa teškog metala koja je adsorbovana po jedinici mase uzorka, izračunata je prema sledećoj jednačini:

$$
q_{a}=\frac{C_{0}-C_{1}}{m} \times V
$$

Gde je:

$\mathrm{q}_{\mathrm{a}}$ - masa teškog metala adsorbovana po jednici mase adsorbenta $(\mathrm{mg} / \mathrm{g})$;

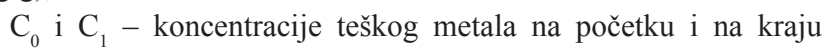
eksperimenta $(\mathrm{mg} / \mathrm{L})$;

$\mathrm{V}$ - zapremina rastvora (L) $\mathrm{i}$

$\mathrm{m}$ - masa adsorbenta $(\mathrm{g})$.

Korišćenjem adsorpcionih izotermi određena je interakcija između rastvora i adsorbenta u stan-ju ravnoteže pri uslovima na kojima se ostvaruje najveći adsorpcioni kapacitet. Fitovanje eksperimen-talnih podataka vršeno je korišćenjem izotermnih modela: Lengmira, Frojndliha i Temkina. Gibsova slobodna energija $\left(\Delta \mathrm{G}^{0}\right)$, entalpija $\left(\Delta \mathrm{H}^{0}\right)$ i entropija $\left(\Delta \mathrm{S}^{0}\right)$ izračunate su pomoću Vant Hofovih ter-modinamičkih jednačina:

$$
\begin{gathered}
\Delta G^{0}=-R T \ln (b) \\
\ln (b)=\frac{\Delta S^{0}}{R}-\frac{\Delta H^{0}}{(R T)}
\end{gathered}
$$

gde je:

$\mathrm{T}$ apsolutna temperatura $\mathrm{u} \mathrm{K}$,

$\mathrm{R}$ je univerzalna gasna konstanta $\left(8,314 \mathrm{~J} \mathrm{~mol}^{-1} \mathrm{~K}^{-1}\right) \mathrm{i}$

$\mathrm{b}$ je bezdimenziona Lengmirova konstanta.

Morfološka struktura adsorbenata određena je metodom rendgenske difrakcione analize (XRD) na uređaju ENRAF NONIUS FR590 KSRD (Bruker AKSS, MA, USA). Strukturna analiza uzoraka izvršena je pomoću infracrvene spktroskopije sa furijeovom transformacijom (FTIR) (Hartmann \& Brovn). FTIR spektri određeni su pre i nakon procesa adsorpcije na sobnoj temperaturi. Radioaktiv-nost FA analizirana je pomoću gamaspektrometra ORTEC - AMETEK sa 8192 kanala, rezolucije 1,95 i relativne efikasnosti $46 \%$ na $1,33 \mathrm{MeV}$ za ${ }^{60} \mathrm{Co}$. 


\section{$3 \quad$ Rezultati i diskusija}

Najveći adsorpcioni kapacitet dobijen je pimenom Lengmirovog modela $25,46 \mathrm{mg} / \mathrm{g}$. Najbolje slaganje rezultata pokazalo se primenom Frojndlihovog modela na $45 \mathrm{C}^{\circ}$ (Tabela 1).

$\mathrm{U}$ Tabeli 2 prikazani su rezultati termodinamičkih parametara.

Tabela 1. Parametri adsorpcionih izotermi uklanjanja As(V) na MFAC

\begin{tabular}{|l|c|c|c|c|}
\hline Model izoterme & $\begin{array}{c}\text { Parametri } \\
\text { modela }\end{array}$ & $\mathbf{2 5} \mathbf{C}^{\circ}$ & $\mathbf{3 5} \mathbf{C}^{\circ}$ & $\mathbf{4 5} \mathbf{C}^{\circ}$ \\
\hline \multirow{3}{*}{ Lengmir } & $\mathrm{q}_{\mathrm{m}}\left(\mathrm{mg} \mathrm{g}^{-1}\right)$ & 23.39 & 24.20 & 25.46 \\
\hline & $\mathrm{b}\left(\mathrm{dm}^{3} \mathrm{~mol}^{-1}\right)$ & 0.0861 & 0.0927 & 0.099 \\
\hline \multirow{3}{*}{ Frojndlih } & $\mathrm{R}^{2}$ & 0.969 & 0.960 & 0.953 \\
\hline \multirow{3}{*}{ Temkin } & $\begin{array}{c}\mathrm{K}_{\mathrm{F}}\left(\mathrm{mg} \mathrm{g}^{-1}\right) \\
\left(\mathrm{dm}^{3} \mathrm{mg}^{-1}\right)^{1 / n}\end{array}$ & 0.166 & 0.143 & 0.137 \\
\hline & $1 / \mathrm{n}$ & 2.792 & 3.000 & 3.165 \\
\hline & $\mathrm{R}^{2}$ & 0.982 & 0.981 & 0.988 \\
\hline & $\mathrm{A}_{\mathrm{T}}\left(\mathrm{dm}^{3} \mathrm{~g}^{-1}\right)$ & 126.3 & 160.6 & 196.8 \\
\hline & $\mathrm{b}\left(\mathrm{J} \mathrm{mol}^{-1}\right)$ & 19.62 & 15.95 & 13.44 \\
\hline & $\mathrm{R}^{2}$ & 0.907 & 0.89188 & 0.902 \\
\hline
\end{tabular}

Tabela 2. Termodinamički parametri za adsorpciju As(V)

\begin{tabular}{|c|c|c|c|c|}
\hline- & & ermodinamičk & i parametri & \\
\hline Temperatura, K & $\Delta \mathrm{G}^{0}\left(\mathrm{KJ} \mathrm{mol}^{-1}\right)$ & $\Delta \mathrm{H}^{0}\left(\mathrm{KJ} \mathrm{mol}^{-1}\right)$ & $\Delta \mathrm{S}^{0}\left(\mathrm{~J} \mathrm{~mol}^{-1} \mathrm{~K}^{-1}\right)$ & $\mathrm{R}^{2}$ \\
\hline 298 & -31.70 & \multirow{3}{*}{5.51} & \multirow{3}{*}{124.80} & \multirow{3}{*}{0.999} \\
\hline 308 & -32.95 & & & \\
\hline 318 & -34.20 & & & \\
\hline
\end{tabular}

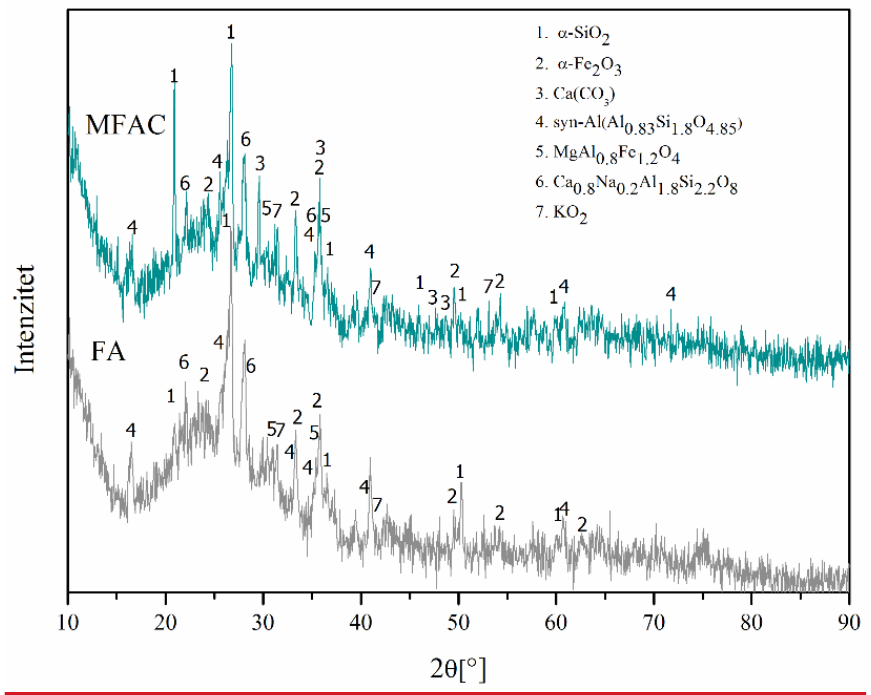

Slika 1: XRD analiza FA i MFAC

Sa porastom temperature vrednosti $\Delta \mathrm{G}^{\mathrm{o}}$ se smanjuju, što ukazuje na spontanost procesa pri višim temperaturama. Pozitivna vrednost entalpije $\left(\Delta H^{\circ}\right)$ ukazuje da je adsorpcija na MFAC endoterman proces. Pozitivna vrednosti entropije $\left(\Delta \mathrm{S}^{\circ}\right)$ ukazujne na težnju stvaranja neuređenog sistema na granici faza između MFAC i rastvora As(V), kao i na mogućnost promena strukture površine adsorbenta. Promena vrednosti entalpije može ukazati na prirodu mehanizma adsorpcije [10], prema čemu dobijena vrednost ukazuje na fizičku adorpciju.

$\mathrm{Na}$ slici 1. prikazani su difraktogrami XRD analize adsorbenata. Struktura materijala je heterogena, dominantan je sadržaj silicijuma $\left(\alpha-\mathrm{SiO}_{2}\right)$, kalcijum natrijum aluminijum silikat$\mathrm{Ca}_{0.8} \mathrm{Na}_{0.2} \mathrm{Al}_{1.8} \mathrm{Si}_{2.2} \mathrm{O}_{8} \mathrm{Ca}_{0.8}$, hematit- $\mathrm{Fe}_{2} \mathrm{O}_{3}$, magnezijum alumnijum gvožđe oksid- $\mathrm{MgAl}_{0.8} \mathrm{Fe}_{1.2} \mathrm{O}_{4}$, kalijumoksid- $\mathrm{KO}_{2}$, kalcijum karbonat $\mathrm{CaCO}_{3}$ i mulit-syn-Al $\left(\mathrm{Al}_{0.83} \mathrm{Si}_{1.8} \mathrm{O}_{4.85}\right)$.

Na slici 2 prikazani su spekti FTIR analize. Položaj odgovarajućih pikova ukazuje na prisustvo minerala na bazi silicijuma i aluminijuma što je u skladu sa XRD analizom. Traka na $775 \mathrm{~cm}^{-1}$ and $456 \mathrm{~cm}^{-1}$ odgovara vibraciji Si-O-Al i Si-O veza.

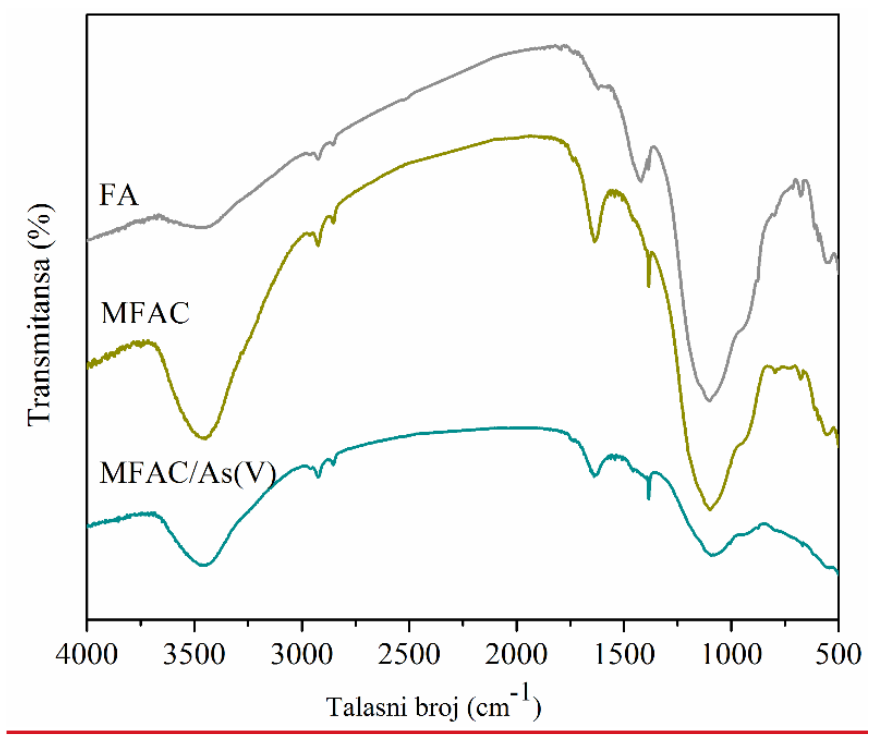

Slika 2: FTIR spektar FA i MFAC pre i MFAC/As(V) nakon procesa adsorpcije

Analiza radioaktivnosti pokazala je prisustvo prirodnih radionuklida čije su vrednosti ispod propisanih graničnih vrednosti prema Pravilnikom o granicama radioaktivne kontaminacije lica, radne i životne sredine i načinu sprovodenja dekontaminacije (Sl. glasnik RS 38/11). Dobijene vrednosti za ${ }^{40} \mathrm{~K}$-kalijum, ${ }^{232} \mathrm{Th}$-torijum, ${ }^{226} \mathrm{Ra}$-radijum, redom su $190 \pm 8,23 \pm 1$ i $31 \pm 2 \mathrm{~Bq} / \mathrm{kg}$.

\section{Zaključak}

$\mathrm{U}$ radu su prikazani rezultati ispitivanja uklanjanja $\mathrm{As}(\mathrm{V})$ iz vodenih rastvora primenom pepela modifikovanog sa cementom. Primenom Lengmirove izoterme dobijen je najbolji adsorpcioni kapacitet od $25,46 \mathrm{mg} / \mathrm{g}$ na $45 \mathrm{C}^{\circ}$, uklanjanje jona najbolje odgovara modelu Frojndlihove izoterme. Adsorpcija As(V) jona na modifikovanom pepelu je spontan i endoterman proces. Rezultati ukazuju da se pepeo može primeniti kao sekundarna sirovina što smanjuje troškove deponovanja. Dalja istraživanja usmerena su ka ponovnoj upotrebi iskorišćenog adsorbenta za izradu građevniskog materijala. 


\section{Zahvalnica}

Istraživanja u ovom radu izvršena su u okviru aktivnosti na projektu TR 34009 i III 43009 koji finansira Ministarstvo prosvete, nauke i tehnološkog razvoja Republike Srbije.

\section{LITERATURA}

[1] M. Karanac, M. Đolić, V. N. Rajaković-Ognjanović, J. Despotović, S. Mandić-Rajčević, D. Povrenović, Uklanjanje teških metala iz vodenih rastvora primenom modifikovanih oblika pepela $i$ šljake iz termoelektrana, in: 29. Međunarodni kongres o procesnoj industriji Procesing '16, Beograd, Srbija, 2017, pp. 227-233.

[2] M. Karanac, D. Povrenović, M. Đolić, J. Despotović, V.N. Rajaković-Ognjanović, Primena pepela $i$ šljake za uklanjanje teških metala, in: Otpadne vode, komunalni čvrsti otpad i opasan otpad, Vršac, Srbija, 2016, pp. 82-87.

[3] N. Karličić, M. Stanojević, D. Radić, M. Bajić, Svojstva pepela koji nastaje sagorevanjem lignita u domaćim termoelektranama značajna za primenu u industriji građevinskog materijala, Procesna Tehnika, SMEITS Beograd, 1 (2014) 34-38.

[4] A. Terzić, L. Pavlović, L. Miličić, Evaluation of Lignite Fly Ash for Utilization as Component in Construction Materials, Int. J. Coal Prep. Util., 33 (2013) 159-180.

[5] M. Karanac, J. Rusmirović, Z. Veličković, D. Stevanović, T. Kovačević, A. Marinković, Uklanjanje arsena iz vodenih rastvora primenom modifikovanog otpadnog PET-a, in: 30. kongres o procesnoj industriji Procesing '17, Beograd, Srbija, 2017, pp. 365-369.

[6] D. Mohan, C.U. Pittman, Jr., Arsenic removal from water/ wastewater using adsorbents--A critical review, Journal of hazardous materials, 142 (2007) 1-53.

[7] D. Budimirović, Z.S. Veličković, V.R. Djokić, M. Milosavljević, J. Markovski, S. Lević, A.D. Marinković, Efficient $\mathrm{As}(\mathrm{V})$ removal by $\alpha-\mathrm{FeOOH}$ and $\alpha-\mathrm{FeOOH} / \alpha-\mathrm{MnO} 2$ embedded PEG-6-arm functionalized multiwall carbon nanotubes, Chem. Eng. Res. Des., 119 (2017) 75-86.

[8] K. Taleb, J. Markovski, Z. Veličković, J. Rusmirović, M. Rančić, V. Pavlović, A. Marinković, Arsenic removal by magnetite-loaded amino modified nano/microcellulose adsorbents: effect of functionalization and media size, Arabian J. Chem., (2016).

[9] W. Sun, J.E. Renew, W. Zhang, Y. Tang, C.-H. Huang, Sorption of $\mathrm{Se}(\mathrm{IV})$ and $\mathrm{Se}(\mathrm{VI})$ to coal fly ash/cement composite: Effect of
Ca 2+ and high ionic strength, Chemical Geology, 464 (2017) 76-83. [10] Z.J. Bajić, Z.S. Veličković, V.R. Djokić, A.A. Perić-Grujić, O. Ersen, P.S. Uskoković, A.D. Marinković, Adsorption Study of Arsenic Removal by Novel Hybrid Copper Impregnated Tufa Adsorbents in a Batch System, CLEAN - Soil, Air, Water, 44 (2016) 14771488.

\section{Autori}

\section{Milica KARANAC,}

Inovacioni centar Tehnološko-metalurškog fakulteta u Beogradu, Univerzitet u Beogradu

mkaranac@tmf.bg.ac.rs

Maja ĐOLIĆ,

Institut za nuklearne nauke Vinča, Univerzitet u Beogradu mdjolic@vinca.rs

\section{Vladana RAJAKOVIĆ-OGNJANOVIĆ}

Građevinski fakultet, Univerzitet u Beogradu

vladana@grf.bg.ac.rs

Zlate VELIČKOVIĆ, Vojna akademija, Univerzitet odbrane u Beogradu zlatevel@yahoo.com

Dragan POVRENOVIĆ, Tehnološko - metalurški fakultet, Univerzitet u Beogradu povrenovic@tmf.bg.ac.rs

\section{Vladimir PAVIĆEVIĆ,}

Tehnološko-metalurški fakultet u Beogradu, Univerzitet u Beogradu vpavicevic@tmf.bg.ac.rs

Aleksandar MARINKOVIĆ, Tehnološko-metalurški fakultet u Beogradu, Univerzitet u Beogradu marinko@tmf.bg.ac.rs
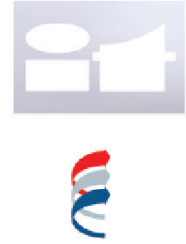

DRUŚTVOZA PROCESNUTEHNIKU
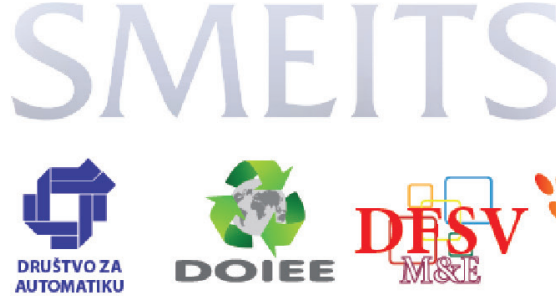
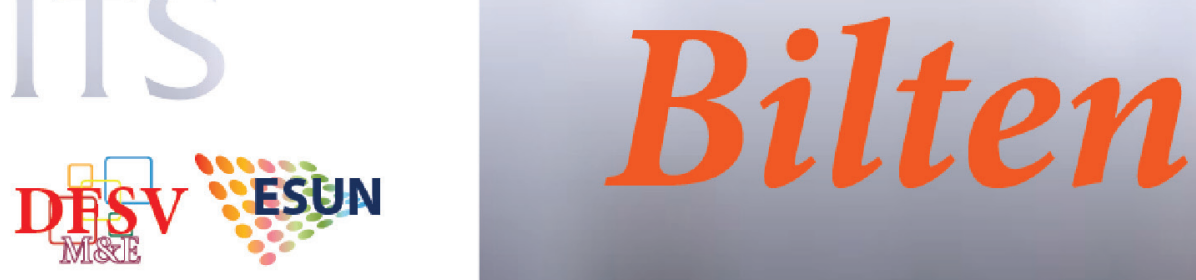